\title{
Comparison of flow diversion with clipping and coiling for the treatment of paraclinoid aneurysms in 115 patients
}

\author{
Michael A. Silva, BA, ${ }^{1}$ Alfred P. See, MD, ${ }^{1}$ Priyank Khandelwal, MD, ${ }^{2}$ Ashutosh Mahapatra, MD, ${ }^{2}$ \\ Kai U. Frerichs, MD, ${ }^{1}$ Rose Du, MD, PhD, ${ }^{1}$ Nirav J. Patel, MD, ${ }^{1}$ and Mohammad A. Aziz-Sultan, MD'1 \\ 1Department of Neurosurgery, Brigham and Women's Hospital, Boston, Massachusetts; and 'Department of Neurology, \\ University of Miami/Jackson Health System, Miami, Florida
}

\begin{abstract}
OBJECTIVE Paraclinoid aneurysms represent approximately $5 \%$ of intracranial aneurysms (Drake et al. [1968]). Visual impairment, which occurs in $16 \%-40 \%$ of patients, is among the most common presentations of these aneurysms (Day [1990], Lai and Morgan [2013], Sahlein et al. [2015], and Silva et al. [2017]). Flow-diverting stents, such as the Pipeline Embolization Device (PED), are increasingly used to treat these aneurysms, in part because of their theoretical reduction of mass effect (Fiorella et al. [2009]). Limited data on paraclinoid aneurysms treated with a PED exist, and few studies have compared outcomes of patients after PED placement with those of patients after clipping or coiling.

METHODS The authors performed a retrospective analysis of 115 patients with an aneurysm of the cavernous to ophthalmic segments of the internal carotid artery treated with clipping, coiling, or PED deployment between January 2011 and March 2017. Postoperative complications were defined as new neurological deficit, aneurysm rupture, recanalization, or other any operative complication that required reintervention.
\end{abstract}

RESULTS A total of 125 paraclinoid aneurysms in 115 patients were treated, including 70 with PED placement, 23 with coiling, and 32 with clipping. Eighteen (14\%) aneurysms were ruptured. The mean aneurysm size was $8.2 \mathrm{~mm}$, and the mean follow-up duration was 18.4 months. Most aneurysms were discovered incidentally, but visual impairment, which occurred in 21 (18\%) patients, was the most common presenting symptom. Among these patients, $15(71 \%)$ experienced improvement in their visual symptoms after treatment, including 14 (93\%) of these 15 patients who were treated with PED deployment. Complete angiographic occlusion was achieved in $89 \%$ of the patients. Complications were seen in $17(15 \%)$ patients, including $10(16 \%)$ after PED placement, $2(9 \%)$ after coiling, and $5(17 \%)$ after clipping. Patients with incomplete aneurysm occlusion had a higher rate of procedural complications than those with complete occlusion $(p=$ 0.02). The rate of postoperative visual improvement was significantly higher among patients treated with PED deployment than in those treated with coiling $(p=0.01)$. The significant predictors of procedural complications were incomplete occlusion ( $p=0.03)$, hypertension, $(p=0.04)$, and diabetes $(p=0.03)$.

CONCLUSIONS In a large series in which patient outcomes after treatment of paraclinoid aneurysms were compared, the authors found a high rate of aneurysm occlusion and a comparable rate of procedural complications among patients treated with PED placement compared with the rates among those who underwent clipping or coiling. For patients who presented with visual symptoms, those treated with PED placement had the highest rate of visual improvement. The results of this study suggest that the PED is an effective and safe modality for treating paraclinoid aneurysms, especially for patients who present with visual symptoms.

https://thejns.org/doi/abs/10.3171/2018.1.JNS171774

KEYWORDS paraclinoid aneurysms; flow diversion; Pipeline Embolization Device; vision; endovascular; vascular disorders

$\mathrm{P}$ ARACLINOID aneurysms are a significant cause of morbidity and death and represent $5 \%$ of intracranial aneurysms. ${ }^{14}$ These aneurysms can be defined as those that affect the region between the cavernous segment of the internal carotid artery (ICA) and the origin of the posterior communicating artery. Although most paracli- noid aneurysms are detected incidentally, they often cause visual symptoms or other cranial nerve palsies because of their proximity to the ophthalmic artery and optic, oculomotor, trochlear, and abducens nerves.

Paraclinoid aneurysms have been treated traditionally with clipping, but endovascular treatment has supplanted

ABBREVIATIONS FET = Fisher exact test; ICA = internal carotid artery; $P E D=$ Pipeline Embolization Device.

SUBMITTED July 21, 2017. ACCEPTED January 10, 2018.

INCLUDE WHEN CITING Published online June 22, 2018; DOI: 10.3171/2018.1.JNS171774. 
surgical treatment in recent years. ${ }^{23}$ In addition to coiling, flow diversion, such as that with the Pipeline Embolization Device (PED), is a newer alternative. The PED is an endoluminal intracranial stent that relies on the principle of flow diversion to stagnate intrasaccular blood flow and promote thrombus formation and thus to exclude the aneurysm sac. ${ }^{16}$ The PED is currently approved for the treatment of large $(>10-\mathrm{mm})$ and giant $(>25-\mathrm{mm})$ wide-necked aneurysms (neck $>4 \mathrm{~mm}$ ) from the petrous to hypophyseal segments of the ICA (see https://www.accessdata.fda.gov/ cdrh_docs/pdf10/P100018B.pdf), and high rates of occlusion and low rates of complications with its use in patients with such aneurysms have been found. 4,6,24,37,40,46

Although these early data on the PED are promising, most PED studies have focused on large and wide-necked aneurysms despite increasing off-label use. The existing literature on paraclinoid aneurysms treated with a PED has been limited and consists mostly of small studies or heterogeneous multicenter data. Few studies have reported specifically on vision outcomes, and very few studies have compared PED placement directly to clipping and coiling. ${ }^{26,30}$ Given the increasing use of PEDs to treat paraclinoid aneurysms, we performed a retrospective analysis of 115 patients (with a total of 125 paraclinoid aneurysms) treated with PED placement, clipping, or coiling. This 2-site study is one of the largest to have directly compared flow diversion to clipping and coiling in a population of patients with such an aneurysm.

\section{Methods}

A retrospective analysis of 115 patients with a paraclinoid aneurysm treated with clipping, coiling, or PED placement between January 2011 and March 2017 was performed. Aneurysms that affected the cavernous to ophthalmic segments of the ICA were included. The patients were treated by 1 of 3 interventionists; all patients who underwent PED deployment were treated by the same interventionist. All the patients were treated at the same institution except for 28 patients who underwent PED placement at a second institution. Institutional review board approval for the study was obtained through the Partners Human Research Committee.

\section{Procedural Details}

Patients who underwent PED deployment were given preoperative medication with aspirin ( $325 \mathrm{mg}$ daily) and clopidogrel (75 mg daily), placed on at least 6 months of postoperative dual-antiplatelet therapy, and then prescribed aspirin $(325 \mathrm{mg}$ ) daily indefinitely after interval angiographic confirmation of stent patency. Neither the responsivity nor the resistance of aspirin and clopidogrel was tested in the absence of thromboembolic symptoms. Endovascular procedures (PED placement or coiling) were performed after the induction of general anesthesia.

\section{Outcomes and Follow-Up}

Complete aneurysm occlusion was determined based on postoperative angiography. Follow-up angiography was performed in most patients 6 months after the procedure and annually thereafter until follow-up imaging was dis- continued. We categorized treatment response as incomplete (Raymond-Roy class II/III) ${ }^{34}$ or complete (RaymondRoy class I) instead of using a more typical Raymond-Roy/ Montreal classification due to our evolving understanding of the treatment mechanism in flow diverters, which is not described as well using the coiling treatment response scale. Postoperative complications were defined as aneurysm rupture, death, ischemic stroke in the immediate postoperative period, or new neurological deficit (transient or permanent), including visual impairment. Visual symptoms were defined as field cuts, blindness, scotoma, amaurosis fugax, decreased acuity, or other deficits thought to have resulted from optic nerve impairment. Diplopia and ophthalmoplegia were classified separately as nonvisual neurological deficits. Patients who presented with or developed new visual symptoms underwent neuroophthalmological assessment when possible.

\section{Statistical Analysis}

All statistical analyses were performed in R 3.0 ( $\mathrm{R}$ Project for Statistical Computing). Comparison between intervention groups was performed using the Fisher exact test (FET) for categorical variables and ANOVA for continuous variables. Bonferroni correction was used for pairwise comparison between treatment groups using the FET, and adjusted $\mathrm{p}$ values were calculated accordingly. Multivariate logistic regression was performed to assess for predictors of aneurysm occlusion or postoperative complications using a $p$ value of 0.05 . Subgroup analyses using multivariate logistic regression were also performed.

\section{Results}

\section{Patient Characteristics}

Between January 2011 and March 2017, 125 aneurysms were treated with clipping, coiling, or PED placement at 1 of 2 institutions by 1 of 3 surgeons. A total of 115 patients (104 female, 11 male) with a paraclinoid aneurysm were treated. Patient characteristics are summarized in Table 1 . The patients were predominantly female $(90 \%)$ with a mean age of 54.5 years (SD 12.1 years). Sixty-two patients with a total of 70 aneurysms underwent treatment with a PED, 23 patients with a total of 23 aneurysms were treated with coiling, and 30 patients with a total of 32 aneurysms were treated with microsurgical clipping. Two patients underwent 2 separate PED deployments for distinct paraclinoid aneurysms. Eight patients with more than 1 paraclinoid aneurysm were treated with a single procedure. We found no statistically significant differences between the patient cohorts treated with any of these interventions.

\section{Aneurysm Characteristics}

One hundred twenty-five aneurysms were treated in total, 70 with PED placement, 23 with coiling, and 32 with clipping. Four patients treated with a PED were treated concurrently with coils. Six coiling procedures were stent assisted. Eighteen (14\%) were ruptured at the time of presentation. Aneurysms in most patients (55 [48\%]) were detected incidentally. Twenty-three (20\%) patients presented with subarachnoid hemorrhage, including from another aneurysm(s), 13 (11\%) presented with isolated vi- 


\begin{tabular}{|c|c|c|c|c|c|c|c|c|c|}
\hline \multirow[b]{2}{*}{ Characteristic } & \multirow[b]{2}{*}{ Total } & \multirow[b]{2}{*}{ PED } & \multirow[b]{2}{*}{ Coil } & \multirow[b]{2}{*}{ Clip } & \multirow{2}{*}{$\begin{array}{c}\text { PED } \\
\text { vs Coil } \\
\text { (adjusted } \\
\text { p value) }\end{array}$} & \multirow{2}{*}{$\begin{array}{l}\text { PED vs Clip } \\
\text { (adjusted } \\
\text { p value) }\end{array}$} & \multirow{2}{*}{$\begin{array}{c}\text { Coil vs Clip } \\
\text { (adjusted } \\
\text { p value) }\end{array}$} & \multicolumn{2}{|c|}{$p$ Value } \\
\hline & & & & & & & & FET & ANOVA \\
\hline Patients & 115 & 62 & 23 & 30 & & & & & \\
\hline Procedures & 117 & 64 & 23 & 30 & & & & & \\
\hline \multicolumn{10}{|l|}{ Sex } \\
\hline Male & $11(10)$ & $6(10)$ & $2(9)$ & $3(10)$ & \multirow{2}{*}{$>0.99$} & \multirow{2}{*}{$>0.99$} & \multirow{2}{*}{$>0.99$} & \multirow{2}{*}{$>0.99$} & \\
\hline Female & $104(90)$ & $56(90)$ & $21(91)$ & $27(90)$ & & & & & \\
\hline Age in yrs (mean [SD]) & $54.5(12.1)$ & $55.3(12)$ & $55.6(10.8)$ & $52(13.3)$ & & & & & 0.4 \\
\hline \multicolumn{10}{|l|}{ Comorbidities } \\
\hline Diabetes & $10(9)$ & $4(6)$ & $4(17)$ & $2(7)$ & $0.2(0.6)$ & $>0.99$ & $0.4(0.6)$ & 0.4 & \\
\hline Smoking & $59(51)$ & $26(42)$ & $13(57)$ & $20(67)$ & $0.3(0.5)$ & $0.04 †(0.1)$ & $0.6(0.6)$ & 0.08 & \\
\hline Hypertension & $47(41)$ & $29(47)$ & $8(35)$ & $10(33)$ & $0.5(0.7)$ & $0.3(0.7)$ & $>0.99$ & 0.3 & \\
\hline Anticoagulation & $4(3)$ & $1(2)$ & $1(4)$ & $2(7)$ & $0.5(0.7)$ & $0.2(0.7)$ & $>0.99$ & 0.9 & \\
\hline Family history* & $23(26)$ & $12(35)$ & $4(17)$ & $7(23)$ & $0.2(0.6)$ & $0.4(0.6)$ & $0.7(0.7)$ & 0.1 & \\
\hline Aneurysms & 125 & 70 & 23 & 32 & & & & & \\
\hline Presentation & & & & & $0.2(0.3)$ & $0.09(0.3)$ & $0.3(0.3)$ & 0.06 & \\
\hline Incidental & $55(48)$ & $25(39)$ & $10(43)$ & $20(67)$ & & & & & \\
\hline $\mathrm{SAH}$ & $23(20)$ & $9(14)$ & $8(35)$ & $6(20)$ & & & & & \\
\hline Visual changes & $13(11)$ & $11(17)$ & $1(4)$ & $1(3)$ & & & \multicolumn{3}{|c|}{0.2} \\
\hline Diplopia & $12(10)$ & $8(13)$ & $1(4)$ & $3(10)$ & & & & & \\
\hline $\begin{array}{l}\text { Other cranial nerve } \\
\text { palsy }\end{array}$ & $4(3)$ & $3(5)$ & $1(4)$ & $0(0)$ & & & & & \\
\hline Ischemic stroke & $2(2)$ & $1(2)$ & $1(4)$ & $0(0)$ & & & & & \\
\hline Other & $6(5)$ & $5(8)$ & $1(4)$ & $0(0)$ & & & & & \\
\hline Location & & & & & $0.4(0.4)$ & $0.0001 \dagger(0.0004 \dagger)$ & $0.002 \dagger(0.003 \dagger)$ & \multicolumn{2}{|l|}{$0.0003 \uparrow$} \\
\hline Ophthalmic & $42(34)$ & $18(26)$ & $6(26)$ & $18(56)$ & & & & & \\
\hline Superior hypophyseal & $42(34)$ & $24(34)$ & $12(52)$ & $6(18.8)$ & & & & & \\
\hline Cavernous & $19(15)$ & $17(24)$ & $2(9)$ & $0(0)$ & & & & & \\
\hline Dorsal variant & $14(11)$ & $5(7)$ & $2(9)$ & $7(22)$ & & & & & \\
\hline Other paraclinoid & $8(6)$ & $6(9)$ & $1(4)$ & $1(3)$ & & & & & \\
\hline Side & & & & & $0.8(0.8)$ & $0.4(0.8)$ & $0.8(0.8)$ & 0.8 & \\
\hline Right & $54(43)$ & $32(46)$ & $10(43)$ & $12(38)$ & & & & & \\
\hline Left & $71(57)$ & $38(54)$ & $13(57)$ & $20(63)$ & & & & & \\
\hline Size in mm (mean [SD]) & $8.2(5.7)$ & $8.4(5.8)$ & $9.7(5.5)$ & $6.5(5.2)$ & & & & & \\
\hline Small $(<15)$ & $110(88)$ & $61(87)$ & $19(83)$ & $30(94)$ & \multirow{3}{*}{$0.6(0.6)$} & \multirow{3}{*}{$0.6(0.6)$} & \multirow{3}{*}{$0.4(0.6)$} & \multirow{3}{*}{0.7} & \\
\hline Large $(15$ to $<25)$ & $11(9)$ & $7(10)$ & $3(13)$ & $1(3)$ & & & & & \\
\hline Giant $(\geq 25)$ & $4(3)$ & $2(3)$ & $1(4)$ & $1(3)$ & & & & & \\
\hline Aneurysms $\leq 10 \mathrm{~mm}$ & $99(79)$ & $54(77)$ & $16(70)$ & $29(91)$ & \multirow{2}{*}{$0.6(0.6)$} & \multirow{2}{*}{$0.2(0.3)$} & \multirow{2}{*}{$0.08(0.2)$} & \multirow{2}{*}{0.1} & \\
\hline Aneurysms >10 mm & $26(21)$ & $16(23)$ & $7(30)$ & $3(9)$ & & & & & \\
\hline
\end{tabular}

$\mathrm{SAH}=$ subarachnoid hemorrhage.

Values are presented as the number (\%) unless stated otherwise. Not all percentage totals reach $100 \%$ because of rounding.

${ }^{*}$ The family history status was unknown for 28 patients treated with PED placement.

† Significant result.

sual symptoms, 12 (10\%) with diplopia, 4 (3\%) with other cranial nerve palsies, 2 (2\%) with stroke, and $6(5 \%)$ presented with other symptoms. We observed no statistically significant differences in presentation between treatment groups (Table 1).

Fifty-four (43\%) aneurysms were right sided, and 69 (55\%) were left sided; we found no significant difference between the groups $(\mathrm{p}=0.8)$. Forty-two $(34 \%)$ aneurysms were of the ophthalmic segment, 42 (34\%) were of the hypophyseal segment, $19(15 \%)$ were cavernous, 14 (11\%) were dorsal variants, and $8(6 \%)$ were other paraclinoid variants (Fig. 1). Ophthalmic segment aneurysms were treated most often with clipping, superior hypophyseal aneurysms with coiling, and cavernous aneurysms with PED 


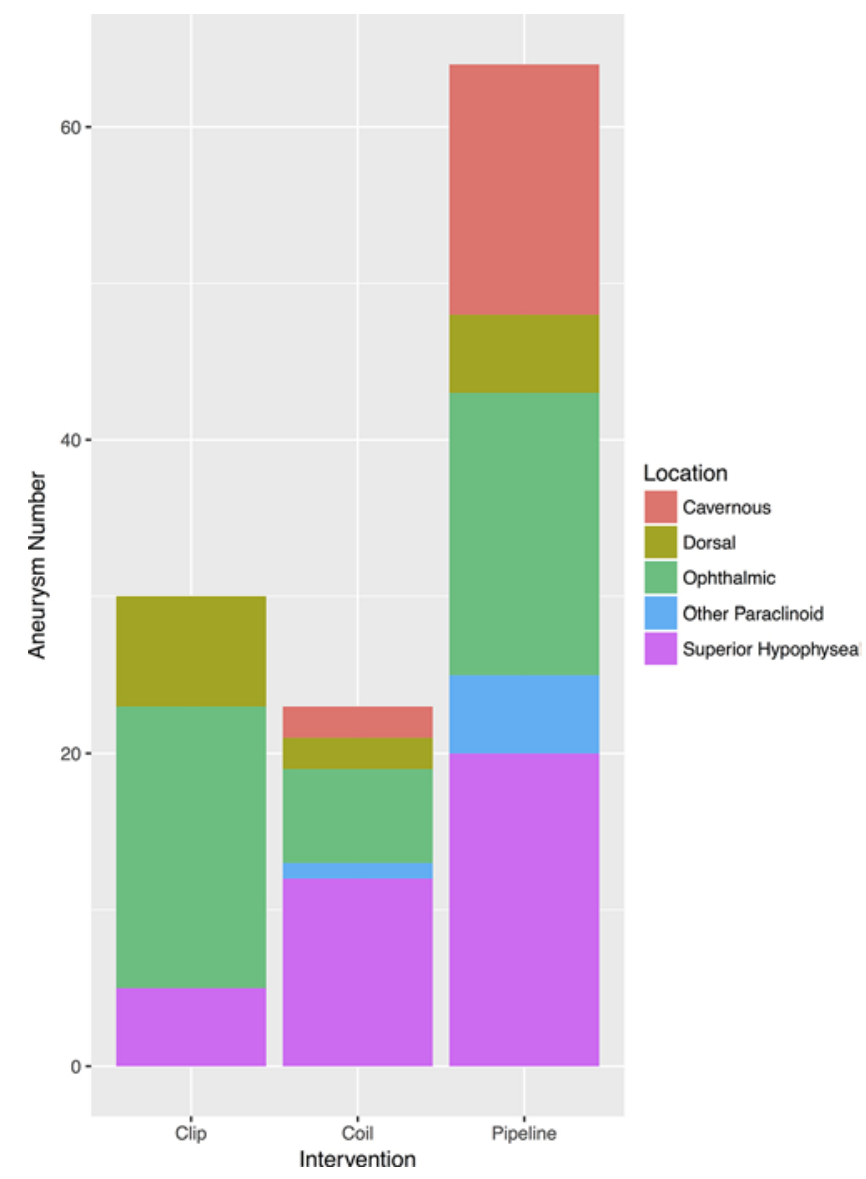

FIG. 1. Number of aneurysms according to location treated with clipping, coiling, or PED. Figure is available in color online only.

placement (combined $\mathrm{p}=0.0003$ ) (Table 1). The mean aneurysm size was $8.2 \mathrm{~mm}$ (SD $5.7 \mathrm{~mm})(8.4 \mathrm{~mm}$ in the PED group, $9.7 \mathrm{~mm}$ in the coiling group, and $6.5 \mathrm{~mm}$ in the clipping group; $\mathrm{p}=0.1$ ) (Fig. 2). One hundred ten aneurysms were small $(<15 \mathrm{~mm}), 11$ were large $(15$ to $<25 \mathrm{~mm})$, and 4 were giant $(\geq 25 \mathrm{~mm})$. Twenty-six (21\%) aneurysms were $>$ $10 \mathrm{~mm}$, including $16(22.9 \%)$ that were treated with a PED. Aneurysm characteristics are summarized in Table 1.

\section{Angiographic Occlusion}

Complete angiographic occlusion at the last follow-up visit was observed in $89 \%$ of the aneurysms, including $89 \%$ of those after PED treatment, $78 \%$ after coiling, and 97\% after clipping (Table 2). PED deployment resulted in a higher rate of occlusion than did coiling $(\mathrm{p}=0.4)$, and clipping yielded a higher rate of occlusion than did coiling $(p=0.2)$, but neither result was statistically significant.

\section{Complications}

Seventeen (15\%) complications occurred, including 10 (16\%) in patients after PED placement, 2 (9\%) in those after coiling, and $5(17 \%)$ in those after clipping (Table 2). We found no significant differences between treatment groups. Serious complications, including rupture, immediate postoperative stroke, and permanent neurological defi- cit, were seen in $12(10 \%)$ patients, including $6(9 \%)$ after PED deployment, 1 (4\%) after coiling, and $5(17 \%)$ after clipping, with no significant difference between groups ( $\mathrm{p}$ $=0.4)$ (Table 2). Delayed postoperative rupture occurred in 1 patient after treatment with a PED. New neurological deficits were observed in 13 patients ( 8 permanent and 5 transient deficits). New visual symptoms were found in 8 patients (4 permanent and 4 transient symptoms). No deaths from procedural complications occurred. Univariate analysis of complications identified only complete occlusion as an associated independent variable. Patients with complete aneurysm occlusion had a significantly lower rate of complications $(11.5 \%)$ than those with incomplete occlusion (38.5\%) $(\mathrm{p}=0.02)$ (Supplementary Table 1). We found no association between aneurysm size $(>10$ or $\leq 10 \mathrm{~mm}$ ) and the rate of complete occlusion or procedural complications (Supplementary Table 2).

\section{Vision Outcomes}

Twenty-one patients presented with visual symptoms; their outcomes are listed in Table 3. Fifteen patients were treated with PED placement (3 of which included the addition of coils), 3 with coiling (1 stent assisted), and 3 with clipping. Postoperative vision was improved in 15 (71\%) patients, including 14 (93\%) of 15 patients treated with a PED. The rate of postoperative visual improvement was significantly higher among patients treated with PED placement than among those treated with coiling $(\mathrm{p}=0.01)$ (Table 3). New visual symptoms were seen in 7 (6\%) patients ( 3 after PED deployment, 1 after coiling, and 3 after clipping), and we found no significant difference between the groups $(\mathrm{p}=0.6)$. In 4 of these patients, symptoms were transient; in the other 3 , symptoms were persistent at the last follow-up visit (Table 3).

\section{Multivariate Regression Analysis}

Multivariate regression analysis including all patient and aneurysm characteristics listed in Table 1 as independent variables revealed hypertension $(p=0.04)$ and incomplete occlusion $(\mathrm{p}=0.03)$ as predictors of procedural complications; diabetes was shown to be protective $(\mathrm{p}=$ $0.03)$. Ophthalmic location was a predictor of permanent complications $(p=0.05)$. An analysis of subgroups based on size or location of the aneurysms did not reveal any significant associations.

\section{Discussion}

To the best of our knowledge, this study is the largest to date to have directly compared PED deployment to coiling and clipping for the treatment of paraclinoid aneurysms. Our cohort included 70 aneurysms treated with a PED by 1 interventionist, which makes it one of the largest and most homogeneous series of patients who have undergone PED placement to date. Complications associated with treating paraclinoid aneurysms, including recanalization, intraoperative or delayed rupture, neurological decline, and incomplete occlusion, that occur after PED placement, clipping, and coiling have been well described. $3,5,7,9,27,31,35$ For the patients who underwent PED placement, we found a high rate of complete angiographic occlusion (89\%), a rate 


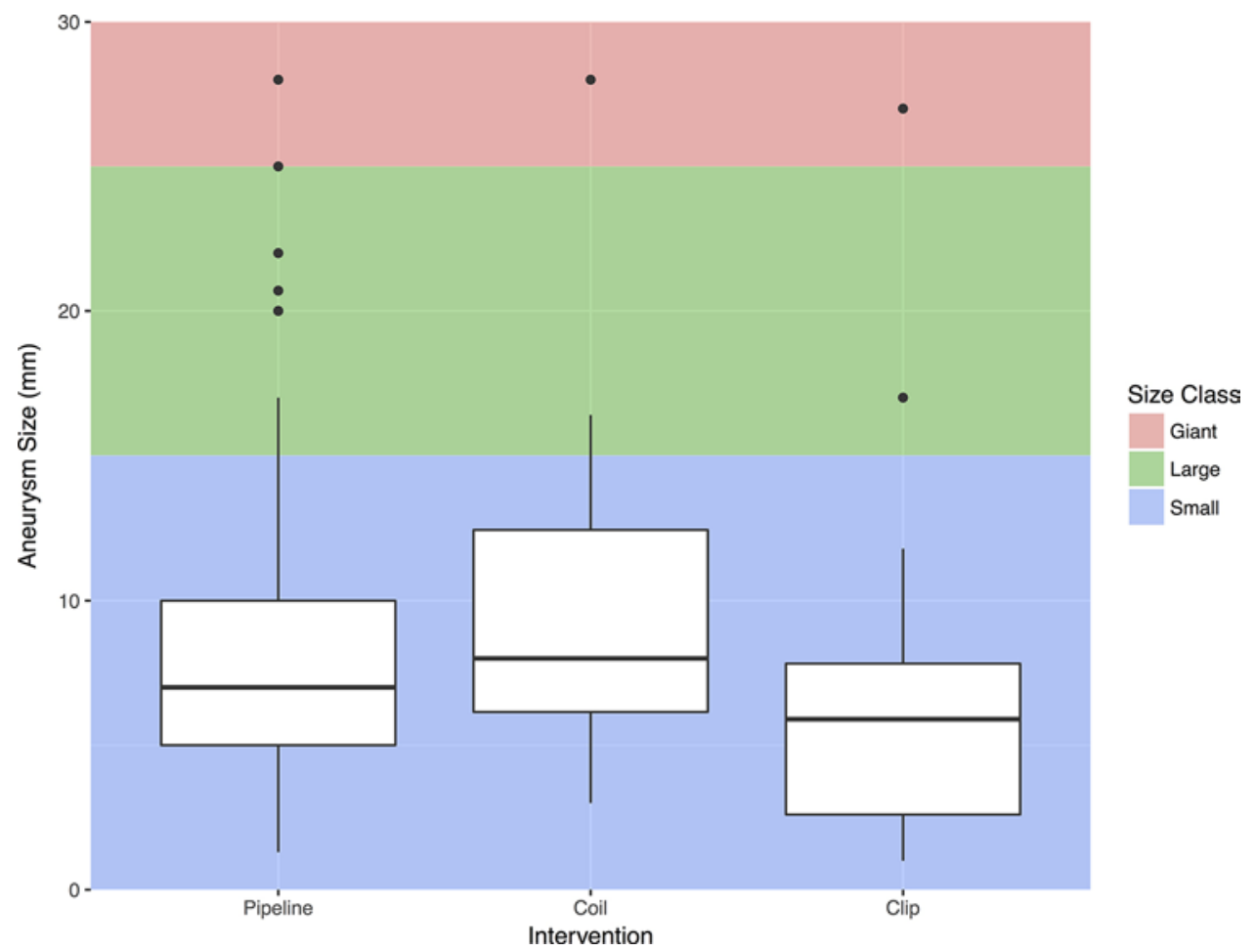

FIG. 2. Boxplot of aneurysm sizes in the PED, coiling, and clipping groups. Most aneurysms were small and were distributed similarly among treatment modalities. Figure is available in color online only.

of permanent procedural complications (9\%) comparable to those after coiling and clipping, no procedure-related deaths, and a significantly higher rate of visual improvement (93\%) after treatment, which suggests that PED deployment is an effective alternative to traditional treatment modalities.

Previous studies focused on the treatment of large and giant wide-necked aneurysms between the petrous and cavernous segments of the ICA, for which the PED was approved originally., 4,24,37,40,46 These promising results led to increasing off-label use of the PED for aneurysms that are not large and not wide necked, and several groups have found similarly strong results after treating small aneurysms $s^{11,17,26}$ and other off-label applications. ${ }^{2,10,13,28,32,36}$

TABLE 2. Comparative outcomes

\begin{tabular}{|c|c|c|c|c|c|c|c|c|c|}
\hline \multirow[b]{2}{*}{ Outcome } & \multirow[b]{2}{*}{ Total } & \multirow[b]{2}{*}{ PED } & \multirow[b]{2}{*}{ Coil } & \multirow[b]{2}{*}{ Clip } & \multirow{2}{*}{$\begin{array}{c}\text { PED vs Coil } \\
\text { (adjusted } p \text { value) }\end{array}$} & \multirow{2}{*}{$\begin{array}{c}\text { PED vs Clip } \\
\text { (adjusted p value) }\end{array}$} & \multirow{2}{*}{$\begin{array}{c}\text { Coil vs Clip } \\
\text { (adjusted } p \text { value) }\end{array}$} & \multicolumn{2}{|c|}{$p$ Value } \\
\hline & & & & & & & & FET & ANOVA \\
\hline Procedures & 117 & 64 & 23 & 30 & & & & & \\
\hline FU duration in mos (mean) & 18.4 & 9.6 & 23.7 & 22.5 & $0.01^{*}$ & $0.02^{*}$ & 0.8 & & $0.01^{*}$ \\
\hline Complete occlusion & $104(89)$ & $57(89)$ & $18(78)$ & $29(97)$ & $0.3(0.4)$ & $0.4(0.4)$ & $0.07(0.2)$ & 0.1 & \\
\hline Complications & $17(15)$ & $10(16)$ & $2(9)$ & $5(17)$ & $0.5(1.0)$ & $1.0(1.0)$ & $0.7(1.0)$ & 0.8 & \\
\hline Rupture & $1(1)$ & $1(2)$ & $0(0)$ & $0(0)$ & & & & & \\
\hline Stroke & $3(3)$ & $2(3)$ & $0(0)$ & $1(3)$ & & & & & \\
\hline \multicolumn{10}{|l|}{ New neurologic deficit } \\
\hline Permanent, nonvisual & $4(3)$ & $2(3)$ & $1(4)$ & $1(3)$ & & & & & \\
\hline Permanent, visual Sxs & $4(3)$ & $1(2)$ & $0(0)$ & $3(10)$ & & & & & \\
\hline Transient, nonvisual & $1(1)$ & $1(2)$ & $0(0)$ & $0(0)$ & & & & & \\
\hline Transient, visual Sxs & $4(3)$ & $3(5)$ & $1(4)$ & $0(0)$ & & & & & \\
\hline Permanent complications & $12(10)$ & $6(9)$ & $1(4)$ & $5(17)$ & $0.7(0.7)$ & $0.3(0.5)$ & $0.2(0.5)$ & 0.400 & \\
\hline Visual complications & $8(7)$ & $4(6)$ & $1(4)$ & $3(10)$ & $1.0(1.0)$ & $0.7(1.0)$ & $0.6(1.0)$ & 0.8 & \\
\hline
\end{tabular}

FU = follow-up; Sxs = symptoms.

Values are presented as the number (\%) unless stated otherwise.

* Significant result. 
TABLE 3. Vision outcomes

\begin{tabular}{|c|c|c|c|c|c|c|c|c|}
\hline Outcome & Total & PED & Coil & Clip & $\begin{array}{c}\text { PED vs Coil } \\
\text { (adjusted } p \text { value) }\end{array}$ & $\begin{array}{c}\text { PED vs Clip } \\
\text { (adjusted } p \text { value) }\end{array}$ & $\begin{array}{c}\text { Coil vs Clip } \\
\text { (adjusted p value) }\end{array}$ & $\begin{array}{l}\text { p Value } \\
\text { (FET) }\end{array}$ \\
\hline Preop visual Sxs (patients) & 21 & 15 & 3 & 3 & $0.4(0.6)$ & $0.2(0.5)$ & $>0.99$ & 0.8 \\
\hline Postop vision & & & & & $0.02^{*}(0.07)$ & $0.2(0.3)$ & $>0.99$ & $0.02^{*}$ \\
\hline Improved & $15(71)$ & $14(93)$ & $0(0)$ & $1(33)$ & $0.005^{\star}\left(0.01^{*}\right)$ & $0.06(0.09)$ & $>0.99$ & $0.002^{*}$ \\
\hline Unchanged & $2(10)$ & $1(7)$ & $1(33)$ & 0 & $0.3(0.9)$ & $>0.99$ & $>0.99$ & 0.500 \\
\hline Declined & $2(10)$ & $0(0)$ & $1(33)$ & $1(33)$ & $0.2(0.3)$ & $0.2(0.3)$ & $>0.99$ & 0.07 \\
\hline Deceased/lost to FU & $2(10)$ & $0(0)$ & $1(33)$ & $1(33)$ & & & & \\
\hline New postop visual Sxs & & & & & $>0.99$ & $0.4(0.9)$ & $0.6(0.9)$ & 0.6 \\
\hline Permanent & $3(3)$ & $0(0)$ & $0(0)$ & $3(10)$ & & & & \\
\hline Transient & $4(3)$ & $3(5)$ & $1(4)$ & $0(0)$ & & & & \\
\hline
\end{tabular}

Values are number (\%) unless stated otherwise.

* Significant result.

Still, the number of studies on use of the PED to treat small aneurysms has been limited, and very few have directly compared patient outcomes with those of patients after coiling or clipping. ${ }^{30}$

The mean aneurysm size in this study was $8.2 \mathrm{~mm}$, which is smaller than the minimum size $(10 \mathrm{~mm})$ for which the PED is approved. In fact, only 17 of the 70 aneurysms treated with a PED (24\%) were larger than $10 \mathrm{~mm}$. Our promising findings suggest that off-label use of the PED for small aneurysms might be as effective as has been demonstrated for large and giant wide-necked aneurysms. Important to note is that outcomes were similarly promising when compared to those of coiling and clipping. In our series, only 1 aneurysm smaller than $5 \mathrm{~mm}$ was coiled. This decision was guided by the interventionist's experience, who had found that small aneurysms are particularly difficult to coil adequately. ${ }^{22,33,38,39,43,45}$

Even fewer groups have studied off-label use of the PED for paraclinoid aneurysms. Burrows et al. ${ }^{8}$ and Griessenauer et al..$^{18,19}$ recently reported that PED deployment might be as efficacious for smaller paraclinoid aneurysms as it is for the large wide-necked aneurysms for which the device is approved. Our results corroborate the findings of these studies and also provide data from a direct comparison of PED placement to coiling and clipping among patients treated over a 6-year period. In 1 of the few other comparative studies, Kim et al. ${ }^{26}$ reported the treatment of 24 paraclinoid aneurysms with PED placement, 24 with clipping, and 41 with stent-assisted coiling. Treatment with a PED resulted in complete aneurysm occlusion in $81 \%$ of the patients, and they found a $13 \%$ rate of posttreatment cranial nerve palsy, compared to a $0 \%$ rate after coiling and a $29 \%$ rate after clipping. ${ }^{26}$ We found similar rates of occlusion and complications in our study.

Paraclinoid aneurysms are in close proximity to the ophthalmic artery, optic nerve, and other cranial nerves; thus, visual deficits are among the most common complications after treatment of these aneurysms. ${ }^{15,21,23}$ It has been hypothesized that physical compression of the optic nerve by the aneurysm sac and thrombosis can play a role in the high rate of visual symptoms observed in patients with such an aneurysm, and this mass effect also might explain other cranial nerve palsies. ${ }^{1,15,16,20,25,41,44}$ The PED is thought to provide the added benefit of diminishing mass effect of the aneurysm sac, ${ }^{16}$ which might prove beneficial for aneurysms in patients who present with symptoms secondary to mass effect. Thus, paraclinoid aneurysms are particularly well suited to capitalize on the proposed mechanistic benefits of the PED over those of other treatment modalities.

As many as $40 \%$ of patients with a paraclinoid aneurysm present with visual symptoms, which can include field defects, decreased acuity, and blindness. ${ }^{12,29,41}$ Our recently published meta-analysis revealed a $38 \%$ rate of visual symptoms among these patients. ${ }^{42}$ PED placement might specifically improve visual outcomes when used to treat paraclinoid aneurysms, according to the results of our meta-analysis, in which we found a high rate of visual improvement (71\%) among patients treated with a PED and similarly low rates of visual complications compared to those after clipping and coiling. ${ }^{42}$ Among the $14 \%$ of patients in this series who presented with visual symptoms, we found a significantly higher rate of vision improvement among those treated with PED deployment than among those treated with coiling or clipping. Although symptomatic visual improvement is just 1 factor to be considered when choosing a treatment modality, the findings of our study suggest that PED use might be particularly beneficial for patients with a paraclinoid aneurysm who present with visual symptoms.

There are several limitations of this study. Use of the PED has increased in frequency and has largely supplanted coiling or clipping for paraclinoid aneurysms, and others, since its introduction. As a result, we often had specific reasons for which coiling or clipping was used instead of PED placement to treat paraclinoid aneurysms, especially in the later years of this study, which is a potential source of selection bias and is especially true for patients who presented with symptoms. The predominance in recent years of PED use for patients with a paraclinoid aneurysm resulted in fewer patients with visual symptoms being treated with coiling or clipping.

Similarly, the increased use of PED deployment in recent years could have introduced selection bias to the population of paraclinoid aneurysms treated with clipping or coiling. For example, the higher frequency of ophthalmic aneurysms in the clipping cohort represents a possible 
source of selection bias. Given the location of these aneurysms, they might be expected to have a greater effect on vision than other paraclinoid aneurysms, which might explain the differences in visual outcomes observed between the groups. The higher proportion of ophthalmic aneurysms among the patients who underwent clipping could also explain the higher rate of complications seen in the clipping cohort. Important to note is that the rates of complications seen after PED placement (16\%), coiling (9\%), and clipping $(17 \%)$ are comparable to those reported from previous studies. ${ }^{17,21,26}$ Other studies have found similar selection bias as a result of the evolving usage of PEDs. ${ }^{26}$

Other trends in our cohort could be sources of confounding. Aneurysms treated with clipping were generally smaller than those treated with coiling or PED placement, although this result was not statistically significant. Moreover, we found a statistically significant difference in aneurysm locations among the treatment modalities ( $p$ $=0.0003)$. Cavernous aneurysms were treated most often with PED deployment, superior hypophyseal aneurysms with coiling, and ophthalmic aneurysms with clipping. This unequal distribution might play a confounding role in explaining the outcomes we observed in the patients after treatment with a PED, coiling, or clipping.

The limited availability of clipping and coiling data from 1 institution contributed to the greater number of PED deployments than of clipping and coiling in the combined cohort. The fact that fewer patients were treated with clipping and coiling than with a PED, especially when many patients at lower risk were treated with PED placement in recent years, might have biased the conclusions that can be drawn from comparison of the 3 treatment modalities. The distribution of PED placements, clipping, and coiling procedures in this study does not necessarily reflect the treatment practices or patterns of modality usage at our institution at any specific time point; the decision-making algorithm for treating paraclinoid aneurysms has evolved with the increasing usage of PEDs and will continue to evolve as new technology and data become available.

\section{Conclusions}

Flow diversion is a safe and effective option for the treatment of paraclinoid aneurysms. In this study, we found a high rate of aneurysm occlusion and a low rate of complications for patients with paraclinoid aneurysms who were treated with PED placement, coiling, or clipping, regardless of aneurysm size. Flow diversion was associated with improved vision outcomes in patients compared to the outcomes in those who underwent coiling or clipping, and it might be beneficial for patients who present with visual symptoms. This study of a large series of patients with a paraclinoid aneurysm is one of the few to have compared PED deployment to traditional treatment modalities, and our results provide further evidence to support the increasing application of flow diversion.

\section{References}

1. Aboukaïs R, Zairi F, Bourgeois P, Thines L, Kalsoum E, Leclerc X, et al: Clinical and imaging follow-up after surgical or endovascular treatment in patients with unruptured carotid-ophthalmic aneurysm. Clin Neurol Neurosurg 125:155-159, 2014

2. Albuquerque FC, Park MS, Abla AA, Crowley RW, Ducruet AF, McDougall CG: A reappraisal of the Pipeline embolization device for the treatment of posterior circulation aneurysms. J Neurointerv Surg 7:641-645, 2015

3. Batjer H, Samson D: Intraoperative aneurysmal rupture: incidence, outcome, and suggestions for surgical management. Neurosurgery 18:701-707, 1986

4. Becske T, Brinjikji W, Potts MB, Kallmes DF, Shapiro M, Moran CJ, et al: Long-term clinical and angiographic outcomes following Pipeline Embolization Device treatment of complex internal carotid artery aneurysms: five-year results of the Pipeline for Uncoilable or Failed Aneurysms Trial. Neurosurgery 80:40-48, 2017

5. Becske T, Kallmes DF, Saatci I, McDougall CG, Szikora I, Lanzino G, et al: Pipeline for uncoilable or failed aneurysms: results from a multicenter clinical trial. Radiology 267:858-868, 2013

6. Briganti F, Napoli M, Tortora F, Solari D, Bergui M, Boccardi E, et al: Italian multicenter experience with flow-diverter devices for intracranial unruptured aneurysm treatment with periprocedural complications-a retrospective data analysis. Neuroradiology 54:1145-1152, 2012

7. Brooks NP, Turk AS, Niemann DB, Aagaard-Kienitz B, Pulfer K, Cook T: Frequency of thromboembolic events associated with endovascular aneurysm treatment: retrospective case series. J Neurosurg 108:1095-1100, 2008

8. Burrows AM, Brinjikji W, Puffer RC, Cloft H, Kallmes DF, Lanzino G: Flow diversion for ophthalmic artery aneurysms. AJNR Am J Neuroradiol [epub ahead of print], 2016

9. Castillo B Jr, De Alba F, Thornton J, DeBrun G, Pulido J: Retinal artery occlusion following coil embolization of carotidophthalmic aneurysms. Arch Ophthalmol 118:851-852, 2000

10. Chalouhi N, Tjoumakaris S, Dumont AS, Gonzalez LF, Randazzo C, Starke RM, et al: Treatment of posterior circulation aneurysms with the pipeline embolization device. Neurosurgery 72:883-889, 2013

11. Chalouhi N, Zanaty M, Whiting A, Yang S, Tjoumakaris S, Hasan D, et al: Safety and efficacy of the Pipeline Embolization Device in 100 small intracranial aneurysms. J Neurosurg 122:1498-1502, 2015

12. Day AL: Aneurysms of the ophthalmic segment. A clinical and anatomical analysis. J Neurosurg 72:677-691, 1990

13. de Barros Faria M, Castro RN, Lundquist J, Scrivano E, Ceratto R, Ferrario A, et al: The role of the Pipeline Embolization Device for the treatment of dissecting intracranial aneurysms. AJNR Am J Neuroradiol 32:2192-2195, 2011

14. Drake CG, Vanderlinden RG, Amacher AL: Carotid-ophthalmic aneurysms. J Neurosurg 29:24-31, 1968

15. Ferrell AS, Lessne ML, Alexander MJ, Shah P, Golshani K, Zomorodi A, et al: Visual complications after stent-assisted endovascular embolization of paraophthalmic and suprasellar variant superior hypophyseal aneurysms: the Duke Cerebrovascular Center experience in 57 patients. World Neurosurg 78:289-294, 2012

16. Fiorella D, Lylyk P, Szikora I, Kelly ME, Albuquerque FC, McDougall CG, et al: Curative cerebrovascular reconstruction with the Pipeline embolization device: the emergence of definitive endovascular therapy for intracranial aneurysms. J Neurointerv Surg 1:56-65, 2009

17. Griessenauer CJ, Ogilvy CS, Foreman PM, Chua MH, Harrigan MR, He L, et al: Pipeline Embolization Device for small intracranial aneurysms: evaluation of safety and efficacy in a multicenter cohort. Neurosurgery 80:579-587, 2017

18. Griessenauer CJ, Ogilvy CS, Foreman PM, Chua MH, Harrigan MR, Stapleton CJ, et al: Pipeline Embolization Device for small paraophthalmic artery aneurysms with an emphasis on the anatomical relationship of ophthalmic artery origin and aneurysm. J Neurosurg 125:1352-1359, 2016 
19. Griessenauer CJ, Piske RL, Baccin CE, Pereira BJA, Reddy AS, Thomas AJ, et al: Flow diverters for treatment of 160 ophthalmic segment aneurysms: evaluation of safety and efficacy in a multicenter cohort. Neurosurgery 80:726-732, 2017

20. Heran NS, Song JK, Kupersmith MJ, Niimi Y, Namba K, Langer DJ, et al: Large ophthalmic segment aneurysms with anterior optic pathway compression: assessment of anatomical and visual outcomes after endosaccular coil therapy. $\mathbf{J}$ Neurosurg 106:968-975, 2007

21. Hoh BL, Carter BS, Budzik RF, Putman CM, Ogilvy CS: Results after surgical and endovascular treatment of paraclinoid aneurysms by a combined neurovascular team. Neurosurgery 48:78-90, 2001

22. Iskandar A, Nepper-Rasmussen J: Endovascular treatment of very small intracranial aneurysms. Interv Neuroradiol 17:299-305, 2011

23. Javalkar V, Banerjee AD, Nanda A: Paraclinoid carotid aneurysms. J Clin Neurosci 18:13-22, 2011

24. Kallmes DF, Brinjikji W, Cekirge S, Fiorella D, Hanel RA, Jabbour P, et al: Safety and efficacy of the Pipeline embolization device for treatment of intracranial aneurysms: a pooled analysis of 3 large studies. J Neurosurg 127:775-780, 2017

25. Kanagalingam S, Gailloud P, Tamargo RJ, Subramanian PS, Miller NR: Visual sequelae after consensus-based treatment of ophthalmic artery segment aneurysms: the Johns Hopkins experience. J Neuroophthalmol 32:27-32, 2012

26. Kim LJ, Tariq F, Levitt M, Barber J, Ghodke B, Hallam DK, et al: Multimodality treatment of complex unruptured cavernous and paraclinoid aneurysms. Neurosurgery 74:51-61, 2014

27. Kobayashi S, Kyoshima K, Gibo H, Hegde SA, Takemae T, Sugita K: Carotid cave aneurysms of the internal carotid artery. J Neurosurg 70:216-221, 1989

28. Kühn AL, Hou SY, Perras M, Brooks C, Gounis MJ, Wakhloo AK, et al: Flow diverter stents for unruptured saccular anterior circulation perforating artery aneurysms: safety, efficacy, and short-term follow-up. J Neurointerv Surg 7:634-640, 2015

29. Lai LT, Morgan MK: Outcomes for unruptured ophthalmic segment aneurysm surgery. J Clin Neurosci 20:1127-1133, 2013

30. Lanzino G, Crobeddu E, Cloft HJ, Hanel R, Kallmes DF: Efficacy and safety of flow diversion for paraclinoid aneurysms: a matched-pair analysis compared with standard endovascular approaches. AJNR Am J Neuroradiol 33:2158-2161, 2012

31. Leipzig TJ, Morgan J, Horner TG, Payner T, Redelman K, Johnson CS: Analysis of intraoperative rupture in the surgical treatment of 1694 saccular aneurysms. Neurosurgery 56:455-468, 2005

32. Lin N, Brouillard AM, Keigher KM, Lopes DK, Binning MJ, Liebman KM, et al: Utilization of Pipeline embolization device for treatment of ruptured intracranial aneurysms: US multicenter experience. J Neurointerv Surg 7:808-815, 2015

33. Lum C, Narayanam SB, Silva L, Shankar J, Bussiere M, Dos Santos MP, et al: Outcome in small aneurysms $(<4 \mathrm{~mm})$ treated by endovascular coiling. J Neurointerv Surg 4:196198,2012

34. Mascitelli JR, Moyle H, Oermann EK, Polykarpou MF, Patel AA, Doshi AH, et al: An update to the Raymond-Roy Occlusion Classification of intracranial aneurysms treated with coil embolization. J Neurointerv Surg 7:496-502, 2015

35. Nanda A, Javalkar V: Microneurosurgical management of ophthalmic segment of the internal carotid artery aneurysms: single-surgeon operative experience from Louisiana State University, Shreveport. Neurosurgery 68:355-371, 2011

36. Navarro R, Brown BL, Beier A, Ranalli N, Aldana P, Hanel RA: Flow diversion for complex intracranial aneurysms in young children. J Neurosurg Pediatr 15:276-281, 2015

37. Nelson PK, Lylyk P, Szikora I, Wetzel SG, Wanke I, Fiorella D: The Pipeline Embolization Device for the intracranial treatment of aneurysms trial. AJNR Am J Neuroradiol 32:34-40, 2011

38. Nguyen TN, Raymond J, Guilbert F, Roy D, Bérubé MD, Mahmoud M, et al: Association of endovascular therapy of very small ruptured aneurysms with higher rates of procedure-related rupture. J Neurosurg 108:1088-1092, 2008

39. Pierot L, Barbe C, Spelle L: Endovascular treatment of very small unruptured aneurysms: rate of procedural complications, clinical outcome, and anatomical results. Stroke 41:2855-2859, 2010

40. Saatci I, Yavuz K, Ozer C, Geyik S, Cekirge HS: Treatment of intracranial aneurysms using the Pipeline flow-diverter embolization device: a single-center experience with longterm follow-up results. AJNR Am J Neuroradiol 33:14361446, 2012

41. Sahlein DH, Fouladvand M, Becske T, Saatci I, McDougall CG, Szikora I, et al: Neuroophthalmological outcomes associated with use of the Pipeline Embolization Device: analysis of the PUFS trial results. J Neurosurg 123:897-905, 2015

42. Silva MA, See AP, Dasenbrock HH, Patel NJ, Aziz-Sultan MA: Vision outcomes in patients with paraclinoid aneurysms treated with clipping, coiling, or flow diversion: a systematic review and meta-analysis. Neurosurg Focus 42(6):E15, 2017

43. Sluzewski M, Bosch JA, van Rooij WJ, Nijssen PC, Wijnalda D: Rupture of intracranial aneurysms during treatment with Guglielmi detachable coils: incidence, outcome, and risk factors. J Neurosurg 94:238-240, 2001

44. Subramanian PS, Miller NR, Renard V, Tamargo RJ: Delayed progressive visual loss following wrapping of bilateral clinoidal aneurysms: recovery of vision and improvement in neuroimaging during corticosteroid treatment. Br J Ophthalmol 89:1666-1668, 2005

45. Suzuki S, Kurata A, Ohmomo T, Sagiuchi T, Niki J, Yamada $\mathrm{M}$, et al: Endovascular surgery for very small ruptured intracranial aneurysms. Technical note. J Neurosurg 105:777780,2006

46. Szikora I, Berentei Z, Kulcsar Z, Marosfoi M, Vajda ZS, Lee $\mathrm{W}$, et al: Treatment of intracranial aneurysms by functional reconstruction of the parent artery: the Budapest experience with the Pipeline Embolization Device. AJNR Am J Neuroradiol 31:1139-1147, 2010

\section{Disclosures}

Dr. Aziz-Sultan is a proctor for Medtronic and Covidien and participates in the training of other physicians in the use of the PED.

\section{Author Contributions}

Conception and design: See, Silva, Khandelwal, Frerichs, Du, Patel, Aziz-Sultan. Acquisition of data: all authors. Analysis and interpretation of data: See, Silva, Khandelwal, Aziz-Sultan. Drafting the article: Silva. Critically revising the article: See, Silva, Mahapatra, Aziz-Sultan. Reviewed submitted version of manuscript: See, Silva, Aziz-Sultan. Approved the final version of the manuscript on behalf of all authors: See. Statistical analysis: See, Silva. Study supervision: Frerichs, Du, Patel, Aziz-Sultan.

\section{Supplemental Information}

Online-Only Content

Supplemental material is available with the online version of the article.

Supplementary Tables 1 and 2. https://thejns.org/doi/suppl/10. 3171/2018.1.JNS171774.

\section{Correspondence}

Alfred P. See: Brigham and Women's Hospital, Harvard Medical School, Boston, MA. psee@partners.org. 